\title{
Peertechz
}
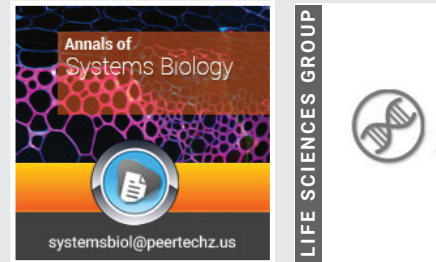

\section{Economic evaluation of}

\section{different biological municipal}

wastewater treatment systems

and implementation of AHP

\section{method based on operating}

Received: 08 May, 2021

Accepted: 07 June, 2021

Published: 09 June, 2021

*Corresponding author: Mohammad Gheibi, Research Associate, Department of Civil Engineering, Ferdowsi University of Mashhad, Iran, Tel: +989152198721; Fax:+985137110979;

E-mail: Mohammadgheibi@ymail.com

Keywords: Wastewater treatment plant; Economic evaluation; Operating costs; Decision-making system; Analytic hierarchy process

https://www.peertechzpublications.com

\section{Check for updates}

\section{costs}

\section{Mohammad Gheibi ${ }^{1 *}$, Benyamin chahkandi², Hashem \\ Kochakzadeh Dandansaz ${ }^{3}$, Zahra Kian ${ }^{4}$ and Reza Aghlmand ${ }^{1}$}

${ }^{1}$ Department of Civil Engineering, Ferdowsi University of Mashhad, Iran

${ }^{2}$ Department of Civil Engineering, University of Tehran, Iran

${ }^{3}$ Department of Civil Engineering, Asrar University of Mashhad, Iran

${ }^{4}$ Department of Chemical Engineering, Amirkabir University of Technology, Tehran, Iran

\begin{abstract}
In large cities, several hundred cubic meters of municipal wastewater is produced every day, which because of high levels of pollution, needs to be treated either for disposal or secondary use. Some of the most important indicators and pollutants that should be reduced to the standard range are VOC, TSS, TDS, BOD ${ }_{5}$, nitrogen, phosphorus, heavy metals, and pathogens. Wastewater treatment plants, which have different capacities and procedures depending on the type and characteristics of the influent and effluent, have large budgets of several hundred million for their life cycle. These costs include construction, maintenance, operation, chemical and biological materials, energy, and amortization. The costs associated with these environmentally essential infrastructures vary according to their treatment processes. This issue leads environmental engineers and policymakers to economic evaluation of various methods. This study with the help of CapdetWorks 2.5 software has discussed three different methods of Complete Mixed Activated Sludge (CMAS), Aerated lagoon, and Oxidation Ditch in wastewater treatment plants in terms of operating costs. Evaluation and implementation of the decision-making system were conducted using Analytic Hierarchy Process (AHP). The results of the analysis showed that aeration ponds are the most optimal option in terms of operating costs with a value of $47.3 \%$. The other two studied methods, namely CMAS and Oxidation Ditch, have a value of $24.9 \%$ and $27.9 \%$, respectively.
\end{abstract}

\section{Introduction}

Water is the main matter for life and living organisms are highly dependent on it in a way that more than $50 \%$ of each living organism is consists of water. Freshwater resources make up a very small part of the planet's water supply (about $3 \%$ ) and of this limited amount, a very small percentage (about $10 \%$ ) is reachable $[1,2]$. This chemical is naturally associated with impurities, and pure water is only reachable by its main reservoirs in polar glaciers because water dissolves or suspends organic and inorganic matter by passing through soil and air or mixing with other liquids. Drinking water is no exception to this rule and contains salts and minerals, but in limited quantities and in a controlled manner; the reduction of these figures to the allowable range takes place in water treatment plants [3-6].

Different uses of water such as washing, sanitation, and 
agriculture lead to the production of wastewater because by the augmentation of waste materials such as urine, feces, detergents, fertilizers, and other pollutants in water and exceeding the standard amount of organic and mineral substances, water becomes useless for previous purposes $[7,8]$. Pollutants existing in wastewater, have the potential to spoil these few resources if released to nature [9-12]. therefore, the amounts of pollutants should be adjusted even for disposal in nature. This is where the importance and necessity of wastewater treatment and the construction of treatment plants become clear. According to the source of its production, wastewater is generally divided into three general categories: urban, industrial and agricultural and it should be noted that the source of production affects the kinds and amount of existing materials and pollutants [4]. Therefore, the treatment plant is designed based on the type of incoming wastewater. One of the most important issues before designing and constructing any wastewater treatment plant is choosing the right treatment process, in a way that a wrong choice can result in a huge increase of costs and even in some cases not achieving the desired outcome [13-17]. The United Nations Environment Program (UNDP) (2015) has evaluated wastewater treatment policies in a report with a comparative approach [18].

In the first step, this research calculates the operating costs of the treatment plant for each of the three common methods of biological treatment, including Complete Mixed Activated Sludge (CMAS), Aerated lagoon, and Oxidation Ditch, and in the next step, the value of each method and the optimal choice is determined. In this regard, the Analytic Hierarchy Process (AHP) is one of the most comprehensive systems designed for decision-making with multiple criteria. This analysis is a flexible and quantitative method for selecting options based on their relative performance for a number of criteria. The purpose of using AHP in the present study is to identify reference options and also to determine their ranking by considering all decision criteria, which are examined in detail in the following sections of the article.

\section{Materials and methods}

\section{Wastewater treatment processes}

Wastewater treatment means lowering the amount of existing organic, mineral, and biological agents in water to the allowable range which includes primary, secondary (biological treatment), and advanced treatment. The designation of these stages may be shorter or longer depending on the incoming wastewater and the selected treatment methods, but the existence of primary and secondary ones is definite [19]. There are different methods to perform each of these steps, which are associated and in combination with other steps during the design process [20].

The biological processes used for wastewater treatment are divided into two important groups: suspended growth and attached growth (biological layer). In the first method, the microorganisms in charge of the purification process are kept suspended in the liquid by proper mixing [21]. The most common suspended growth process used for municipal wastewater treatment is activated sludge, which makes oxidation ditch and aerated/non-aerated lagoons the next priority. Therefore, the studied processes are limited to three processes of Complete mixed activated sludge (CMAS), oxidation ditch, and aeration lagoons, which are most used in Iran. Flowchart Process for the three under consideration processes is shown in Figure 1a-c.

The CMAS process has a continuous flow and has an initial settling tank to remove coarse sediments and apply additional load to the aeration tank (Figure 1a). The most important advantage of this process is neutralizing the effects of shock and the most important disadvantage is the possibility of the growth of filamentous microorganisms and an increase in the volume of sludge. The oxidation ditch process consists of a round or elliptical channel equipped with aeration and mixing equipment in which the incoming wastewater enters the inner streams in a spiral that decreases the amount of organic matter and pollutants accumulatively (Figure $1 \mathrm{~b}$ ). Aerated ponds or lagoons also act like activated sludge systems, except that there is no sludge return in this process and the resulting sludge settles and will be evacuated after a long time (about 10 years). Lagoons can be with or without aeration, when aeration exists algae disappear and get replaced by biologically active masses (Figure 1c) [22].

\section{Economic simulation}

Performing economic calculations before decision-making processes (especially in infrastructural projects which involve large-scale costs) is necessary [23]. In order to perform these calculations, besides using instructions and performing calculations manually, utilizing provided models and software (which are published in local, periodic, and public forms) is so useful and efficient. Economic models provide the opportunity to compare different alternatives by performing calculations in a short period of time. Economic simulations and calculations of treatment plant operating costs have been performed using CapdetWorks2.5 software.

\section{Analytic hierarchy process}

These days, most issues left to managers have various dimensions and are formulated with several criteria. In other words, most of the decisions made by managers are affected by various quantitative and qualitative factors, most of which are in conflict with each other that makes them try to choose the best decision between several available options. Naturally solving multi-criteria decision-making problems is complex and not easily possible, especially when some of the criteria in question are in conflict with each other; increasing the desirability of one can reduce the desirability of the other. As a result, methods called multi-criteria decision making (MCDM) and especially multi-attribute decision making (MADM) have been developed to help solve these problems [4]. Decisionmaking methods are used to evaluate different effective criteria and set priorities, and all have the same process and framework of goal setting, determining possible alternative solutions, evaluating the feasibility of solutions, evaluating the consequences and outcomes of each, and finally selecting. Different methods could be employed for Multi-criteria decision making and weighting of criteria the most important 


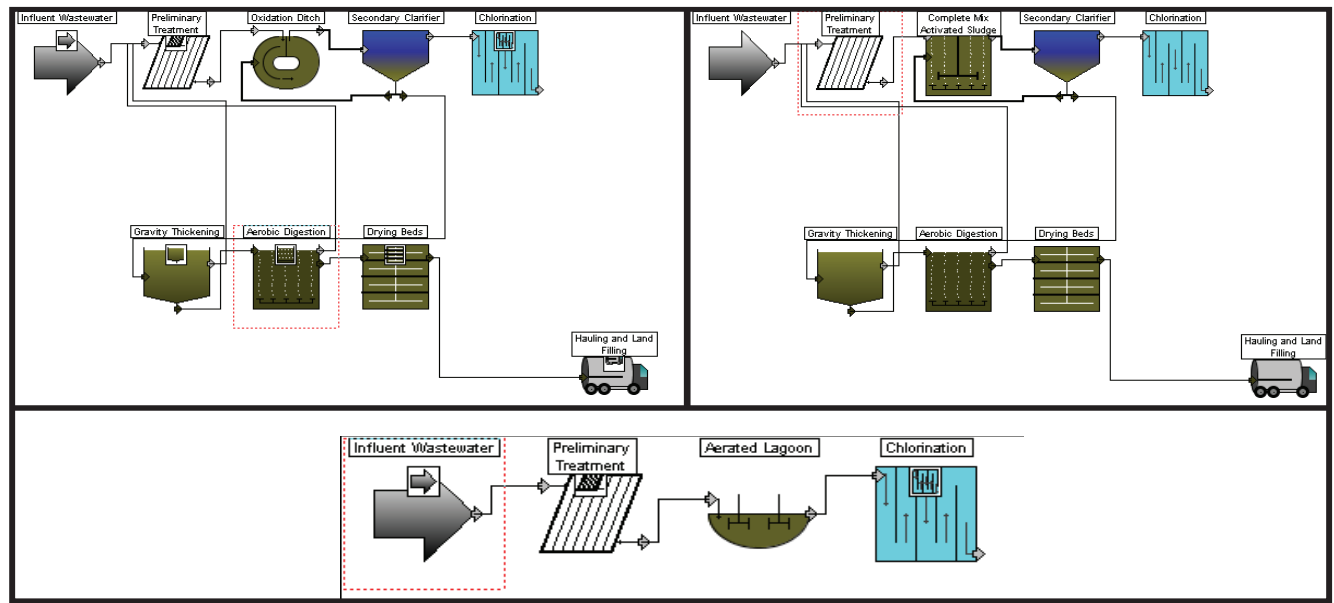

Figure 1: a) Flow process diagram of CMAS (top right); b) Oxidation ditch (top left); c) Aerated lagoon (bottom).

of which are AHP, BOT, VICOR, DEMATEL, ELECTRE, TOPSIS, and SAW [4]. The Analytic Hierarchy Process (AHP) is one of the most comprehensive systems designed for multiple criteria decision-making. This method makes it possible to formulate the problem hierarchically, taking into account different criteria quantitatively and qualitatively. The ability to involve different options in decision-making and the possibility of analyzing the sensitivity of criteria and sub-criteria in this process is one of its main advantages. This method is based on the pairwise comparison, which facilitates judgments and calculations and shows the degree of consistency and incompatibility of the decision [2]. The method is based on a hierarchical structure to assist the analyst in managing critical aspects of the problem, within a tree-like hierarchical structure that reduces complex decisions to some simple comparisons and rankings [12]. The main reasons for using this method can be summarized as follows [4]:

- Having an effective and operational approach to consider non-structural and complex decisions;

- Pairwise comparisons in the AHP method allow decision-makers to extract the weight of any criteria or the ranking of each option from paired matrices, and a large number of criteria are able to be considered;

- Helping decision-makers to incorporate critical aspects of the problem into a hierarchical structure to shape flexibility based on the problem;

- The hierarchical structure of the AHP method resulted from pairwise comparisons of independent judgments, is preferable to efforts that prioritize all decisions and criteria simultaneously.

The purpose of using the analytic hierarchy process is to identify reference options as well as determining their ranking by considering all decision criteria simultaneously [2]. This analysis is a flexible and quantitative method for selecting options based on their relative performance over a number of criteria. Overall, the AHP method typically involves the following six steps:
1. Non-structural definition of the problem and clear expression of the expected goals and results

2. decomposition of a complex problem into decision elements (detailing criteria and options)

3. Using pairwise comparisons between decision elements in order to create comparison matrices

4. Estimating the relative weights of decision elements

5. Calculating the incompatibility rate of matrices to ensure the consistency of decision maker's judgments

6. Aggregate the weighted decision elements to get the final ranking of all options

\section{Results and discussion}

Economic simulation based on municipal wastewater input with the specifications presented in Table 1 (which is equivalent to the average specifications of five wastewater treatment plants in Mashhad) and other required data has been chosen in accordance with US design standards which are almost the same as software default data.

Economic analysis was performed after defining three

Table 1: Influent characteristics and temperature condition.

\begin{tabular}{|c|c|c|}
\hline Parameter & Allocated amount & unit \\
\hline Average flowa & 41100 & $\mathrm{~m} 3 / \mathrm{d}$ \\
\hline Minimum flow & 30800 & $\mathrm{~m} 3 / \mathrm{d}$ \\
\hline Maximum flow & 113000 & $\mathrm{~m} 3 / \mathrm{d}$ \\
\hline Suspended solids & 220 & $\mathrm{mg} / \mathrm{L}$ \\
\hline Volatile solids \% & 75 & $\%$ \\
\hline BOD & 300 & $\mathrm{mg} / \mathrm{L}$ \\
\hline Soluble BOD & 210 & $\mathrm{mg} / \mathrm{L}$ \\
\hline COD & 600 & $\mathrm{mg} / \mathrm{L}$ \\
\hline Soluble COD & 420 & $\mathrm{mg} / \mathrm{L}$ \\
\hline Average summer temperature & 24 & degree C \\
\hline Average winter temperature & 10 & degree C \\
\hline
\end{tabular}


target processes, to which their flow process diagrams are referred in Figure $1(\mathrm{a}-\mathrm{c})$, and assigning the required software parameters in relation to the flow characteristics and general conditions of the treatment plant, the most important of which mentioned in Table 1. The results are reflected in Figure 2 and according to the economic calculation chart; operating costs for wastewater treatment plants are divided into six categories including performance, maintenance, materials, chemical, energy, and amortization. As presented in the diagram, the aeration lagoons have the highest energy consumption and the lowest cost for materials, performance, and maintenance. On the other hand, the Complete mixed activated sludge process, which is briefly represented by CMR, meaning complete mixing reactor, has the highest amortization and operating costs. Also, the oxidation ditch process has the lowest amortization and energy consumption.

Another important cost parameter that is always considered for comparison is the construction cost [24], which according to the results of economic analysis, for each of the three treatment processes; the construction cost is as shown in Figure 3. The highest construction cost is allocated to the CMAS activated sludge treatment plant with a figure of $84,600,000$ dollars, and the other two processes require approximately the same and 34 million dollars. Therefore, due to the variety of factors affecting operating costs, in order to make the right decision for choosing the optimal option, decision-making methods should be implemented.

Meetings with experienced experts of Mashhad Water and Sewerage Department using brainstorming techniques were conducted to determine the importance and evaluation coefficients of the six operating cost parameters (operating costs, maintenance, materials and consumables, chemicals, energy, and amortization). As shown in Figure $4 \mathrm{~b}$, the highest value was assigned to the maintenance with $26.9 \%$ and the lowest to amortization costs with $1.8 \%$.

The Analytic Hierarchy Process (AHP) was implemented using Expert Choice 11 software and using the valuation figures obtained in joint meetings and the calculated costs shown in Figure 2. The results which are depicted in Figure $4 \mathrm{a}$ show that the highest value among the biological treatment plants belongs to aeration lagoons with a value of $47.3 \%$. Oxidation stream and CMAS with values of $27.9 \%$ and $24.9 \%$ respectively are in the next priorities. Of course, as shown in Figure 5, these values are based on the sensitivity defined for each operating cost parameter, and if they change at another time or place, or any other Involved factors, the value of each option fluctuates consequently.

\section{Conclusion}

The need for wastewater treatment is not hidden from anyone due to the high degree of physical, chemical, and biological pollution, and this is completely possible by wastewater treatment plants. However, the high cost of these large-scale projects has led experts to find the most appropriate option that optimally meets the technical, economic, and environmental goals. The results of this research show that the highest construction cost was allocated to the CMAS

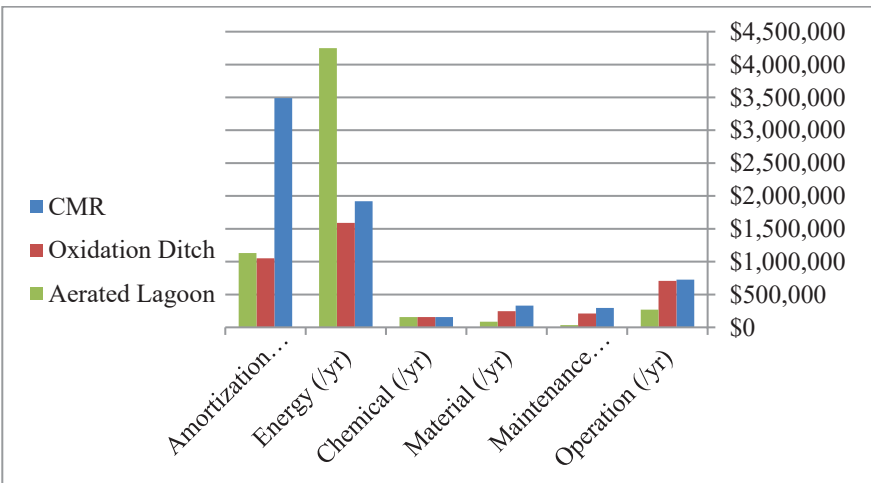

Figure 2: Operating cost parameter values for 3 selected processes.

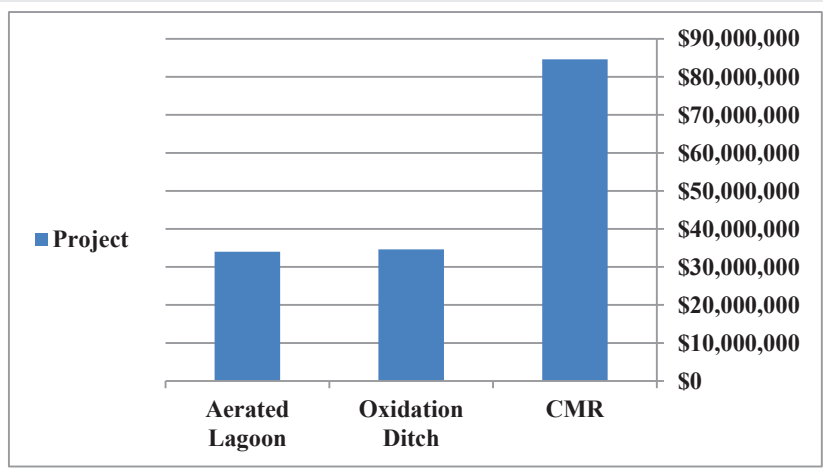

Figure 3: Construction cost for each treatment method.

$21.9 \%$ Operation
$26.9 \%$ Maintenance
$13.6 \%$ Material
$25.4 \%$ Chemical
$10.4 \%$ Energy
$1.8 \%$ Amortization

$24.9 \%$ CMR

27.9\% Oxidation Ditch

$47.3 \%$ Lagoon

$\begin{array}{llllllllllllllllllllll}0 & .1 & 2 & .3 & .4 & .5 & .6 & .7 & 8 & .9 & 1 & 0 & .1 & .2 & .3 & .4 & .5 & .6 & .7 & .8\end{array}$

Figure 4: a) Evaluation of each treatment method based on operating costs. (right) b) Evaluation of each operating cost parameter.

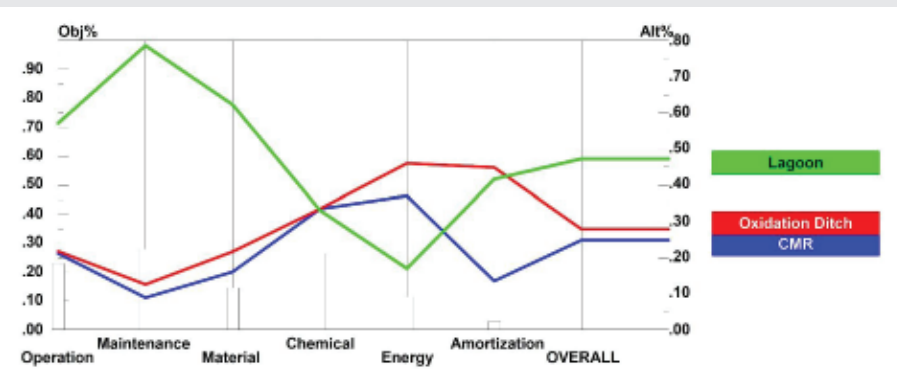

Figure 5: Value commensurate with the degree of parameter sensitivity for each method.

treatment method by $\$ 83,700,000$ and the highest operating cost parameter belongs to the energy in aeration lagoons with a figure of $\$ 4,215,000$ and amortization for CMAS by $\$ 3,485,000$. Weighing the operating cost parameters and performing the hierarchical analysis process showed that aeration lagoons are the most optimal option with a value of $47.3 \%$. The other two 
studied methods, oxidation ditch, and CMAS scored a value of $27.9 \%$ and $24.9 \%$, respectively.

\section{References}

1. Abbasi N, Ahmadi M, Naseri M (2021) Quality and cost analysis of a wastewate treatment plant using GPS- $X$ and CapdetWorks simulation programs. Journal of Environmental Management 284: 111993. Link: https://bit.ly/3iqDMqE

2. Arif AUA, Sorour MT, Aly SA (2020) Cost analysis of activated sludge and membrane bioreactor WWTPs using CapdetWorks simulation program: Case study of Tikrit WWTP (middle Iraq). Alexandria Engineering Journal 59: 46594667. Link: https://bit.ly/3iwU80u

3. Tian X, Richardson RE, Tester JW, Lozano JL, You F (2020) Retrofitting Municipal Wastewater Treatment Facilities toward a Greener and Circular Economy by Virtue of Resource Recovery: Techno-Economic Analysis and Life Cycle Assessment. ACS Sustainable Chemistry \& Engineering 8: 13823-13837. Link: https://bit.ly/3z7YtxD

4. Mirabi M, Karrabi M, Gheibi M (2019) An economic analysis of industrial wastewater treatment systems using multi-attribute decision-making methods (case study: Toos Industrial Estate, Mashhad, Iran). Desalination and Water Treatment 146: 131-140. Link: https://bit.ly/34XiuJk

5. Naghedi R, Moghaddam MRA, Piadeh F (2020) Creating functional group alternatives in integrated industrial wastewater recycling system: A case study of Toos Industrial Park (Iran). Journal of Cleaner Production 257: 120464. Link: https://bit.ly/3x20XKm

6. Corominas L, Byrne D, Guest JS, Hospido A, Roux P, et al. (2020) The application of life cycle assessment (LCA) to wastewater treatment: A best practice guide and critical review. Water Research 184: 116058. Link: https://bit.ly/3g6yAXL

7. Zhou Y, Meng J, Zhang M, Chen S, He B, et al. (2019) Which type of pollutants need to be controlled with priority in wastewater treatment plants: Traditional or emerging pollutants?. Environ Int 131: 104982. Link: https://bit.ly/3cqkzlh

8. Kaur J, Punia S, Kumar K (2017) Need for the advanced Technologies for Wastewater Treatment. In Advances in Environmental Biotechnology. Springer, Singapore 39-52. Link: https://bit.ly/3cmAMaX

9. Nakkasunchi S, Hewitt NJ, Zoppi C, Brandoni C (2021) A review of energy optimization modelling tools for the decarbonisation of wastewater treatment plants. Journal of Cleaner Production 279: 123811. Link: https://bit.ly/3im5WTX

10. Jafarinejad S (2020) A framework for the design of the future energy-efficient, cost-effective, reliable, resilient, and sustainable full-scale wastewater treatment plants. Current Opinion in Environmental Science \& Health 13: 91100. Link: https://bit.ly/3gg2tnh

11. Hilares RT, Atoche-Garay DF, Pagaza DAP, Ahmed MA, Andrade GJC, et al. (2021) Promising physicochemical technologies for poultry slaughterhouse wastewater treatment: A critical review. Journal of Environmental Chemical Engineering 9: 105174. Link: https://bit.ly/3cmg5vW

12. Hellal MS, Abou-Elela SI (2021) Simulation of a passively aerated biological filter (PABF) immobilized with non-woven polyester fabric (NWPF) for wastewater treatment using GPS-X. Water and Environment Journal. Link: https://bit.ly/3irnmOW

13. Bhatt $A H$, Tao $L$ (2020) Economic perspectives of biogas production via anaerobic digestion. Bioengineering 7: 74. Link: https://bit.ly/2T9HsTn

14. Bashar R, Gungor K, Karthikeyan KG, Barak P (2018) Cost effectiveness of phosphorus removal processes in municipal wastewater treatment. Chemosphere 197: 280-290. Link: https://bit.ly/3w6cius

15. Abdel-Magid HIM (2015) Development of a Decision Support System for Hydraulic and Structural Design of Water \& Wastewater Treatment Units (Doctoral dissertation, Sudan University of Science and Technology). Link: https://bit.ly/34Y7aNc

16. Garrido-Baserba M, Vinardell S, Molinos-Senante M, Rosso D, Poch M (2018) The economics of wastewater treatment decentralization: a techno-economic evaluation. Environmental Science \& Technology 52: 8965-8976. Link: https://bit.ly/3cpm3MF

17. O'Dwyer E, Wang H, Wang AJ, Shah N, Guo M (2018) Optimisation of wastewater treatment and recovery solutions in industrial parks. In Computer Aided Chemical Engineering 43: 1407-1412. Link: https://bit.ly/3cleOp1

18. Morelli B, Cashman S, Ma XC, Garland J, Turgeon J, et al. (2018) Effect of nutrient removal and resource recovery on life cycle cost and environmental impacts of a small scale water resource recovery facility. Sustainability 10 : 1-19. Link: https://bit.ly/3im6kSp

19. Tian X, Richardson RE, Tester JW, Lozano JL, You F (2020) Retrofitting Municipal Wastewater Treatment Facilities toward a Greener and Circular Economy by Virtue of Resource Recovery: Techno-Economic Analysis and Life Cycle Assessment. ACS Sustainable Chemistry \& Engineering 8: 13823-13837. Link: https://bit.ly/3z7YtxD

20. Theregowda R, Hsieh MK, Walker ME, Landis AE, Abbasian J, et al. (2013) Life cycle costs to treat secondary municipal wastewater for reuse in cooling systems. Journal of Water Reuse and Desalination 3: 224-238. Link: https://bit.ly/3w2MVd8

21. Manea EE, Robescu LD, Panaitescu V (2016) Using Simulation for Optimising Biological Nutrients Removal Design in Wastewater Treatment Plants. REVISTA DE CHIMIE 67: 2291-2294. Link: https://bit.ly/3g10jqR

22. Manea EE, Robescu LD, Panaitescu V (2016) Using Simulation for Optimising Biological Nutrients Removal Design in Wastewater Treatment Plants. Revista de Chimie -Bucharest- Original Edition 67: 2291-2294. Link: https://bit.ly/3g10jqR

23. Kamble SJ, Singh A, Kharat MG (2017) A hybrid life cycle assessment based fuzzy multi-criteria decision making approach for evaluation and selection of an appropriate municipal wastewater treatment technology. Euro-Mediterranean Journal for Environmental Integration 2: 9. Link: https://bit.ly/34Zrpdw

24. Saha AK, Choudhury S, Majumder M (2017) Performance efficiency analysis of water treatment plants by using MCDM and neural network model. MATTER: International Journal of Science and Technology 3: 27-35. Link: https://bit.ly/2RyCOO

Copyright: @ 2021 Gheibi M, et al. This is an open-access article distributed under the terms of the Creative Commons Attribution License, which permits unrestricted use, distribution, and reproduction in any medium, provided the original author and source are credited. 